\title{
Evidence suggests vocal production learning in a cross-fostered Risso's dolphin (Grampus
} griseus)

Livio Favaro ${ }^{1,2}$, Silvana Neves ${ }^{1,3}$, Stefano Furlati ${ }^{4}$, Daniela Pessani ${ }^{2}$, Vidal Martin ${ }^{3}$, and Vincent M. Janik $^{1 *}$

${ }^{1}$ Sea Mammal Research Unit, School of Biology, University of St Andrews, Fife KY16 8LB, UK

${ }^{2}$ Department of Life Sciences and Systems Biology, University of Torino, 10123 Turin, Italy

${ }^{3}$ SECAC, Society for the Study of Cetaceans in Canary Archipelago, Apartados de Correos 49 de Arrecife de Lanzarote, Spain

${ }^{4}$ Oltremare Marine Park, 47838 Riccione, Rimini, Italy

${ }^{*}$ corresponding author

e-mail: vi@st-andrews.ac.uk

Phone: +441334 467214

FAX: +44 1334463443

\section{Acknowledgments}

We would like to thank the marine mammal staff of the Oltremare Marine Park, especially Daniele Zanzi and Barbara Biancani. We are also grateful to Giulia Bemporad for help with data collection, Thomas Götz and Volker Deecke for providing helpful comments and Olivier Pierre Friard for technical support. Livio Favaro was supported by the University of Torino through a MIUR PhD scholarship. All procedures performed in studies involving animals were in accordance with the ethical standards of the institution or practice at which the studies were conducted. 


\section{Abstract}

Vocal learning is a rare skill in mammals and we have limited information about the contexts in which they use it. Previous studies suggested that cetaceans in general are skilled at imitating sounds but only few species have been studied to date. To expand this investigation to another species and to investigate the possible influence of the social environment on vocal learning, we studied the whistle repertoire of a female Risso's dolphin (Grampus griseus) that was stranded at an early age and was subsequently raised in a group of bottlenose dolphins (Tursiops truncatus). We show that this cross-fostered animal produced vocal signals more akin to those of its Tursiops poolmates than those of Risso's dolphins in the wild. This is one of very few systematic crossfostering studies in cetaceans, and the first to suggest vocal production learning in the Risso's dolphin. Our findings also suggest that social experience is a major factor in the development of

40 the vocal repertoire in this species.

41 Keywords Bioacoustics, Bottlenose dolphin, Grampus griseus, Risso's dolphin, Signature 42 whistles, Tursiops truncatus 


\section{Introduction}

Vocal production learning, the ability to modify the acoustic structure of vocalisations after hearing a model sound, is a significant step in the evolution of complexity in communication systems (Janik and Slater 2000). Humans make extensive use of vocal learning to develop speech, but this ability is rare in other animals. Indeed, while many birds are excellent vocal learners, non-human primates and many other mammals are not (Janik and Slater 1997). The only terrestrial, non-human mammals where we find strong evidence for this skill are bats (Knörnschild et al. 2010) and elephants (Poole et al. 2005; Stoeger et al. 2012). However, considerable evidence for vocal production learning can be found in marine mammals (Janik 2014). The best studied species here is the bottlenose dolphin (Richards et al. 1984), where each individual uses vocal learning to develop its own unique signature whistle (Janik and Sayigh 2013). These animals invent their own unique whistle modulation pattern seemingly by modifying whistles they heard early in life (Fripp et al. 2005). In baleen whales, vocal learning contributes to the development of song (Janik 2014) and pinnipeds have been found to copy sounds of other individuals (Reichmuth and Casey 2014). Despite abundant evidence for vocal learning in a few marine mammals, we still know little about vocal learning in the other species and its role in their social lives. To address these gaps, we investigated whether and how vocal learning can influence the vocal repertoire of a member of a species where learning has not been studied, a Risso's dolphin, that has been crossfostered by a group of bottlenose dolphins. If vocal learning was important in social integration, we would expect the Risso's dolphin to deviate from its natural repertoire to match aspects of the bottlenose dolphin vocalizations and their use.

\section{Methods}

\section{Animal history}

In summer 2005, a mother-calf pair of Risso's dolphins was found in the harbour of Ancona (44 $\left.62^{\prime} \mathrm{N}, 13^{\circ} 50^{\prime} \mathrm{E}\right)$, Italy. The calf was a female, approximately 6 months of age. Both animals were transported to a local dolphin facility for veterinary treatments where they were kept in isolation. Nevertheless, the adult dolphin died after two days due to serious health complications. The 
orphaned calf was kept in quarantine for 30 days and subsequently moved to the Oltremare marine park in Riccione, Italy. In this new facility, the Risso's dolphin was initially kept with a group of 11 adult bottlenose dolphins ( 7 males, 4 females). Six of the males were moved to another facility in 2008. At the time of our study in 2011, the bottlenose dolphin group consisted of 1 male, 4 females and a one year old male calf. Three of these animals were caught in the Western Atlantic Ocean over 25 years ago, and moved to Italy from Cuba and the USA. All others were born in captivity in Italy.

\section{Data collection at Oltremare marine park}

We conducted behavioural observations on close contact swimming $(<1 \mathrm{~m})$ of the Oltremare dolphins over several days from 30 Nov 2009 to 26 Feb 2010. This behaviour is an indicator of a close social relationship in dolphins (Connor et al. 2000). Dolphins were observed as one group (66 hours) or in two groups separated by a gate (32 hours with 2 males separated from the rest of the group). The Risso's dolphin was in the same pools as its preferred social partner, a female named Pelé, in all observation periods. In April 2011, we collected audio and video recordings during 30 different recording sessions over 14 consecutive days. We used an acoustic recording array consisting of four $\mathrm{HTI}-94-\mathrm{SSQ}$ hydrophones (frequency response $2 \mathrm{~Hz}$ to $30 \mathrm{kHz} \pm 1 \mathrm{~dB}$ ). The hydrophone output signals were recorded with a Tascam DR-680 digital recorder (sampling rate 96 $\mathrm{kHz}$ ). During recording sessions, the Risso's dolphin and the bottlenose dolphins were free to swim in the main pool and all four holding pools of the facility. However, we analysed only segments when one animal was isolated from the group by choosing to swim alone in one of three holding pools that we fitted with individual hydrophones. This allowed us to match vocalisations to the emitter by using a time-of-arrival difference analysis of the acoustic signals to hydrophones (Janik et al. 2000). Over the period of recordings, the whistles of the Risso's dolphin were collected in 17 separate sessions, while each of the six poolmates was recorded for an average of $4 \pm 2$ (mean \pm SD) different sessions.

\section{Acoustic recordings of wild Risso's dolphins}


Acoustic recordings in the Canary Islands were conducted continuously on a dispersed 4hydrophone array, recording to a laptop with an Edirol FA-101 sound card. The acoustic array had 3 hydrophones tensioned to chains at $2 \mathrm{~m}$ of depth (2 HTI-96-MIN and one HTI-94-SSQ, frequency response $2 \mathrm{~Hz}$-to- $30 \mathrm{kHz} \pm 1 \mathrm{~dB}$ ), and a fourth hydrophone at $10 \mathrm{~m}$ of depth (SRD hydrophone $\mathrm{HS} / 150$, frequency response $1 \mathrm{kHz}-\mathrm{to}-100 \mathrm{kHz} \pm 1 \mathrm{db}$ ). Recordings were collected for as long as possible in a sea state of 3 or less (Beaufort scale) in dry weather using sampling rates of $96 \mathrm{kHz}$ (33\% of recordings) and $192 \mathrm{kHz}$ (67\% of recordings). Signal to noise ratio (SNR) was calculated for each of the 115 recorded whistles in a total recording time of 45 hours in the presence of Risso's dolphins. Only 62 of these had a SNR of $6 \mathrm{~dB}$ or above which was our criterion for inclusion in the analysis.

\section{Acoustic analysis}

Audio segments containing whistles were visually selected by inspection of spectrograms (Hanning window, FFT size 512, 100\% window width) using Adobe Audition 2.0. For each whistle, we extracted the pitch contour of the fundamental frequency using the beluga toolbox (available for download at: http://biology.st-andrews.ac.uk/soundanalysis/) for MATLAB ${ }^{\circledR}$. From each whistle contour extracted with beluga, we measured the following 12 acoustic parameters using automatized procedures in $M A T L A B^{\circledR}$ : start frequency, end frequency, minimum frequency, maximum frequency, mean frequency, frequency range (maximum - minimum), duration, time to minimum frequency, time to maximum frequency, number of inflections in the contour (i.e. any change of slope from positive to negative or vice versa), number of steep sections in the contour (i.e. frequency change $>500 \mathrm{~Hz}$ between one point and the following), and number of steps in the contour (i.e. steep sections preceded or followed by at least 25 ms of frequency modulation of less than $100 \mathrm{~Hz})$.

\section{Statistical analysis}

After parameter standardization, we performed a principal component analysis (PCA) on all acoustic parameters using an orthogonal varimax rotation. The PCA reduced the original set of 
acoustic measurements to a new set of uncorrelated principal components (PCs). The scores of these PCs were then used to calculate pairwise Euclidean distances for each whistle of the Risso's dolphin with those of the captive bottlenose dolphins and wild conspecifics. All analyses were performed in SPSS v. 20 (SPSS, Inc. 2010).

\section{Results}

Each of the bottlenose dolphins primarily used one individually distinctive and unique signature whistle when swimming alone (time analysed = 01 h 15 m 59 s; $N_{\text {whistles }}=151$ (8-40 per animal)) (Fig. 1a). The cross-fostered Risso's dolphin also produced only one unique whistle type (Fig. 1b) when swimming in isolation (time analysed $=02 \mathrm{~h} 54 \mathrm{~m} 24 \mathrm{~s} ; \mathrm{N}_{\text {whistles }}=192$ ), similar to the use of signature whistles found in bottlenose dolphins. Descriptive statistics of the whistle parameters for this type are presented in Table 1a. Interestingly, recurring whistle contours in our sample of wild Risso's dolphin whistles were rare (Fig. 1c) (time analysed $=45 \mathrm{~h}$; $\mathrm{N}_{\text {whistles }}=62$ ).

The PCA reduced the 12 acoustic parameters measured from the fundamental frequency to four independent PCs. These four components explained $81.93 \%$ of the total variance $(\mathrm{PC} 1=$ $24.56 \%$, PC2 $=22.88 \%$, PC3 $=19.82 \%$, PC4 = 14.68\%). Table 2 shows the factor loadings for each principal component. In particular, the main separating PC (PC1) represented primarily maximum frequency, mean frequency, frequency range, duration and time to maximum frequency. In the space defined by the PCs, the signature whistles of the Risso's dolphin made a distinctive cluster within the range of variation of bottlenose dolphin vocalisations, and they were separated from the cluster made by whistles from wild conspecifics recorded in the Canary Archipelago (Fig. 2). Mean Euclidean distances indicated that similarity was higher between the whistles of the captive Risso's dolphin and those of the bottlenose dolphins $(2.87 \pm 0.004$; mean \pm SE pairwise distances) than between the whistles of the captive and the wild Risso's dolphins $(3.074 \pm 0.009)$. Interestingly, the whistle parameters of the Risso's dolphin whistle most closely matched those of an adult female (Pelé) that she spent most of her contact time with (time spent at more than $1 \mathrm{~m}$ from conspecifics: $74 \%$, time close to Pelé only: $15 \%$, time close to other dolphins: $11 \%$ ) and those 
of the one adult male that stayed in the pool for the whole study period even though she was not observed to interact with him.

\section{Discussion}

The evidence presented here suggests that Risso's dolphins are capable of vocal learning. We analysed the whistle repertoire of a female that became orphaned at an early age and grew up in a community of captive bottlenose dolphins. We found that the cross-fostered Risso's dolphin produced almost exclusively one whistle type when in isolation, similar to the use of signature whistles found in bottlenose dolphins (Janik and Sayigh 2013). Interestingly, recurring whistle contours in our sample of wild Risso's dolphin whistles were rare. Together with the very low whistle rate we found for wild Risso's dolphins in the Canary Islands, this may indicate an absence of signature whistles in wild Risso's dolphins. However, Risso's dolphin behaviour in the Canaries may differ from that in other geographic locations. A signature whistle has been found in one other captive Risso's dolphin but this animal was also housed with bottlenose dolphins (Caldwell et al. 1969).Killer whales have also been found to change their vocal behaviour when housed with bottlenose dolphins (Musser et al. 2014), further supporting the importance of the social environment for repertoire development in delphinids. It remains to be seen whether Risso's dolphins use signature whistles when with conspecifics.

Overall, our results show that the whistles of the cross-fostered Risso's dolphin were much closer to those of its bottlenose dolphin pool mates than to wild Risso's dolphins from the Canary Islands (Figure 2). This was also confirmed by the analysis of Euclidean distances, chosen as a similarity measure. While the Canary Island population may differ from Risso's dolphins in the Adriatic Sea, a comparison of our data with published data from wild Risso's dolphin from the Azores and from Scotland (Rendell et al. 1999) also suggests that the cross-fostered individual used its pool mates as a model for its whistle. Table 3 shows that average values for start, end, minimum, maximum, and mean frequency of the captive Risso's dolphin whistles were considerably closer to the average bottlenose dolphin whistles from its pool than to those from 
184 these other conspecific populations. Little is known about wild Risso's dolphin vocalizations and 185 their social organization appears to be different from that of well-known vocal learners like 186 bottlenose dolphins or killer whales (Orcinus orca) (Hartmann et al. 2008). Risso's dolphins live in 187 relatively stable, non-matrilineal groups. Thus, it is difficult to speculate how Risso's dolphins would 188 use vocal learning in the wild.

In conclusion, our results provide evidence that the cross-fostered Risso's dolphin developed a 191 signature whistle and used overall whistle parameters that were more similar to bottlenose 192 dolphins than to those used by wild Risso's dolphins. Cross-fostering is one of the few strong 193 approaches to the study of vocal learning and as shown here can add information on the role of 194 social partners in its usage. Our study only describes one animal and can therefore only suggest 195 the influence of vocal learning on whistle development. Changes in vocalizations could be 196 achieved through copying as in vocal production learning, or through selection of pre-existing 197 vocalization patterns as would be the case in contextual learning. The large differences in 198 parameters, especially in start frequency and frequency range, between the cross-fostered animal 199 and the three wild populations of Risso's dolphins suggest that this is a case of vocal production 200 learning rather than using already existing whistles from a pre-existing repertoire. However, future 201 studies need to address the role of signature vocalizations in this species as well as the mechanism of learning with a larger sample size. 


\section{References}

Fripp D, Owen C, Quintana-Rizzo E, Shapiro A, Buckstaff K, Jankowski K, Wells R, Tyack P (2005) Bottlenose dolphin (Tursiops truncatus) calves appear to model their signature whistles on the signature whistles of community members. Anim Cogn 8: 17-26.

Caldwell DK, Caldwell MC, Miller JF (1969) Three brief narrow-band sound emissions by a captive male Risso's dolphin, Grampus griseus. Bull So Calif Acad Sci 68: 252-256

Connor RC, Wells RS, Mann J, Read AJ (2000) The bottlenose dolphin: social relationships in a fission-fusion society. In: Mann J, Connor RC, Tyack PL, Whitehead H (eds) Cetacean societies: field studies of dolphins and whales. The University of Chicago Press, Chicago, pp $91-126$

Hartmann KL, Visser F, Hendriks AJE (2008) Social structure of Risso's dolphins (Grampus griseus) at the Azores: a stratified community based on highly associated social units. Can J Zool 86: 294-306

Janik VM (2014) Cetacean vocal learning and communication. Curr Opin Neurobiol 28: 60-65 Janik VM, Sayigh LS (2013) Communication in bottlenose dolphins: 50 years of signature whistle research. J Comp Physiol A 199:479-489.

Janik VM, Slater PJB (1997) Vocal learning in mammals. Adv Study Behav 26: 59-99.

Janik VM, Slater PJB (2000) The different roles of social learning in vocal communication. Anim Behav 60: 1-11.

Janik VM, Van Parijs SM, Thompson PM (2000) A two-dimensional acoustic localization system for marine mammals. Mar Mammal Sci 16: 437-447.

Knörnschild M, Nagy M, Metz M, Mayer F, von Helversen O (2010) Complex vocal imitation during ontogeny in a bat. Biol Lett 6:156-159.

Musser WB, Bowles AE, Grebner DM, Crance JL (2014) Differences in acoustic features of vocalizations produced by killer whales cross-socialized with bottlenose dolphins. J Acoust Soc Am 136: 1990-2002. 
230 Poole JH, Tyack PL, Stoeger-Horwath AS, Watwood S (2005) Elephants prove capable of vocal 231 learning. Nature 434:455-456.

232 Reichmuth C, Casey C (2014) Vocal learning in seals, sea lions and walruses. Curr Opin Neurobiol $233 \quad 28: 66-71$

234 Rendell LE, Matthews JN, Gill A, Gordon JCD, MacDonald DW (1999) Quantitative analysis of 235 tonal calls from five odontocete species, examining interspecific and intraspecific variation. J $236 \quad$ Zool 249:403-410.

237 Richards DG, Wolz JP, Herman LM (1984) Vocal mimicry of computer-generated sounds and 238 vocal labeling of objects by a bottlenosed dolphin, Tursiops truncatus. J Comp Psychol 98: $239 \quad 10-28$.

240 Stoeger AS, Mietchen D, Oh S, de Silva S, Herbst CT, Kwon S, Fitch WT (2012) An Asian 241 elephant imitates human speech. Curr Biol 22: 2144-2148. 


\section{Tables}

Table 1. (a) Descriptive statistics of whistle parameters. (b) Mean values and standard deviation of whistle parameters from captive bottlenose and Risso's dolphins and wild Risso's dolphins recorded in the Azores and Scotland by Rendall et al. (1999). Shaded boxes indicate parameters in which the cross-fostered Risso's dolphin was more similar to the captive bottlenose dolphins than to the wild Risso's dolphins.

\begin{tabular}{|c|c|c|c|c|c|c|c|c|c|c|c|c|c|}
\hline & & $\begin{array}{c}\text { Start } \\
\text { frequency } \\
(\mathrm{Hz})\end{array}$ & $\begin{array}{c}\text { End } \\
\text { frequency } \\
(\mathrm{Hz})\end{array}$ & $\begin{array}{l}\text { Minimum } \\
\text { frequency } \\
(\mathrm{Hz})\end{array}$ & $\begin{array}{l}\text { Maximum } \\
\text { frequency } \\
(\mathrm{Hz})\end{array}$ & $\begin{array}{c}\text { Mean } \\
\text { frequency } \\
(\mathrm{Hz})\end{array}$ & $\begin{array}{l}\text { Frequency } \\
\text { range }(\mathrm{Hz})\end{array}$ & $\begin{array}{l}\text { Duration } \\
\text { (ms) }\end{array}$ & $\begin{array}{c}\text { Time to } \\
\text { minimum } \\
\text { frequency (ms) }\end{array}$ & $\begin{array}{c}\text { Time to } \\
\text { maximum } \\
\text { frequency (ms) }\end{array}$ & $\begin{array}{l}\text { Number of } \\
\text { inflections in } \\
\text { the contour }\end{array}$ & $\begin{array}{l}\text { Number of } \\
\text { steep } \\
\text { sections }\end{array}$ & $\begin{array}{l}\text { Number of } \\
\text { steps in the } \\
\text { contour }\end{array}$ \\
\hline \multicolumn{14}{|c|}{ 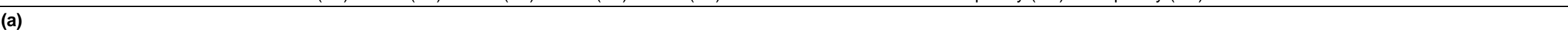 } \\
\hline \multirow{2}{*}{$\begin{array}{l}\text { Risso's dolphins } \\
\text { recorded in the Canary } \\
\text { Archipelago }(n=62)\end{array}$} & Mean & 11461 & 12810 & 10094 & 15205 & 12471 & 5110 & 506 & 228 & 298 & 1 & 1 & 0 \\
\hline & St.Dev. & 2781 & 4310 & 2476 & 3932 & 2823 & 2976 & 220 & 248 & 248 & 2 & 2 & 2 \\
\hline \multirow{2}{*}{$\begin{array}{l}\text { Cross-fostered Risso's } \\
\text { dolphin }(n=192)\end{array}$} & Mean & 6006 & 7769 & 5771 & 16852 & 12372 & 11080 & 757 & 95 & 615 & 1 & 2 & 2 \\
\hline & St.Dev. & 1015 & 1300 & 872 & 1474 & 852 & 1708 & 114 & 239 & 117 & 0 & 1 & 1 \\
\hline \multirow{2}{*}{$\begin{array}{l}\text { Bottlenose dolphin Pelé } \\
\qquad(\mathrm{n}=26)\end{array}$} & Mean & 6748 & 6863 & 5165 & 19080 & 11283 & 13915 & 432 & 360 & 252 & 3 & 10 & 7 \\
\hline & St.Dev. & 833 & 1179 & 1116 & 1515 & 926 & 1450 & 100 & 152 & 172 & 1 & 4 & 3 \\
\hline \multirow{2}{*}{$\begin{array}{l}\text { Bottlenose dolphin } 2 \\
\qquad(\mathrm{n}=40)\end{array}$} & Mean & 8276 & 9680 & 6187 & 9952 & 7014 & 3764 & 130 & 16 & 181 & 1 & 2 & 1 \\
\hline & St.Dev. & 600 & 894 & 139 & 1002 & 339 & 984 & 34 & 9 & 114 & 0 & 1 & 0 \\
\hline \multirow{2}{*}{$\begin{array}{l}\text { Bottlenose dolphin } 3 \\
\qquad(\mathrm{n}=8)\end{array}$} & Mean & 8818 & 10635 & 4471 & 10635 & 7048 & 6164 & 1353 & 712 & 231 & 2 & 4 & 3 \\
\hline & St.Dev. & 380 & 814 & $1 ß 28$ & 814 & 204 & 752 & 130 & 49 & 432 & 1 & 3 & 2 \\
\hline \multirow{2}{*}{$\begin{array}{l}\text { Bottlenose dolphin } 4 \\
\qquad(n=27)\end{array}$} & Mean & 16115 & 6620 & 6576 & 17688 & 10941 & 11111 & 539 & 500 & 39 & 1 & 1 & 1 \\
\hline & St.Dev. & 1248 & 110 & 124 & 982 & 299 & 984 & 46 & 50 & 16 & 1 & 1 & 1 \\
\hline \multirow{2}{*}{$\begin{array}{l}\text { Bottlenose dolphin } 5 \\
\qquad(n=28)\end{array}$} & Mean & 6862 & 13110 & 6034 & 15407 & 10023 & 9373 & 701 & 232 & 461 & 3 & 7 & 5 \\
\hline & St.Dev. & 1572 & 3799 & 1247 & 2668 & 1467 & 2788 & 155 & 250 & 181 & 1 & 4 & 3 \\
\hline \multirow{2}{*}{$\begin{array}{l}\text { Bottlenose dolphin } 6 \\
(\mathrm{n}=22)\end{array}$} & Mean & 9096 & 5380 & 5214 & 11150 & 7385 & 5936 & 788 & 729 & 82 & 1 & 1 & 0 \\
\hline & St.Dev. & 1605 & 347 & 344 & 1737 & 647 & 1577 & 132 & 123 & 55 & 1 & 1 & 1 \\
\hline \multicolumn{14}{|l|}{ (b) } \\
\hline \multirow{2}{*}{$\begin{array}{l}\text { Risso's dolphins } \\
\text { recorded in the Azores ( } \mathrm{n} \\
=82) \text { and Scotland }(\mathrm{n}= \\
1182)\end{array}$} & Mean & 12100 & 10830 & 8830 & 13440 & 11300 & 4610 & 530 & & & & & \\
\hline & St.Dev. & 2160 & 3330 & 2710 & 2690 & 2290 & 2680 & 260 & & & & & \\
\hline \multirow{2}{*}{$\begin{array}{l}\text { Cross-fostered Risso's } \\
\text { dolphin }(n=192)\end{array}$} & Mean & 6006 & 7769 & 5771 & 16852 & 12372 & 11080 & 757 & & & & & \\
\hline & St.Dev. & 1015 & 1300 & 872 & 1474 & 852 & 1708 & 114 & & & & & \\
\hline \multirow{2}{*}{$\begin{array}{l}\text { Oltremare bottlenose } \\
\text { dolphins }(n=151)\end{array}$} & Mean & 9258 & 8611 & 5819 & 14129 & 9065 & 8309 & 521 & & & & & \\
\hline & St.Dev. & 3507 & 3149 & 940 & 3998 & 2011 & 4024 & 324 & & & & & \\
\hline
\end{tabular}


Table 2. Results of the principal component analysis with varimax rotation. The table shows factor loadings of the acoustic parameters on the principal components showing eigenvalues > 1 (PC1-PC4) extracted from the PCA. Bold text indicates the largest factor loadings $(r>0.5)$.

\begin{tabular}{llllr}
\hline \multirow{2}{*}{ Acoustic parameter } & \multicolumn{3}{c}{ Principal Component } \\
\cline { 2 - 4 } & \multicolumn{1}{c}{$\mathbf{c}$} & \multicolumn{1}{c}{$\mathbf{3}$} & \multicolumn{1}{c}{$\mathbf{0 . 7 2 8}$} \\
\hline Start frequency & -0.072 & -0.269 & $\mathbf{0 . 5 2 9}$ & 0.210 \\
End frequency & 0.009 & 0.124 & $\mathbf{0 . 8 3 1}$ & 0.180 \\
Minimum frequency & 0.098 & -0.283 & $\mathbf{0 . 8 8 5}$ & -0.043 \\
Maximum frequency & $\mathbf{0 . 8 7 9}$ & 0.317 & 0.194 & 0.119 \\
Mean frequency & $\mathbf{0 . 8 7 7}$ & 0.014 & 0.376 & -0.061 \\
Frequency range & $\mathbf{0 . 7 4 2}$ & 0.442 & -0.312 & -0.048 \\
Duration & $\mathbf{0 . 6 1 4}$ & -0.049 & -0.475 & $-\mathbf{0 . 8 5 2}$ \\
Time to minimum frequency & -0.014 & 0.020 & -0.285 & $\mathbf{0 . 6 2 7}$ \\
Time to maximum frequency & $\mathbf{0 . 6 4 4}$ & 0.070 & -0.179 & -0.058 \\
Number of inflections in the contour & 0.086 & $\mathbf{0 . 7 2 0}$ & 0.001 & 0.040 \\
Number of steep slope sections & 0.126 & $\mathbf{0 . 9 5 2}$ & -0.044 & -0.105 \\
Number of contour jumps & 0.157 & $\mathbf{0 . 9 2 1}$ & 0.077 & \\
\hline
\end{tabular}




\section{Figure Captions}

Fig. 1 Pitch contours extracted for the signature whistles of the six bottlenose dolphins (a; * indicates the whistles of Pelé) and the Risso's dolphin (b). The contours of the whistles recorded from wild Risso's dolphins in the Canary Archipelago are presented as a comparison (c)

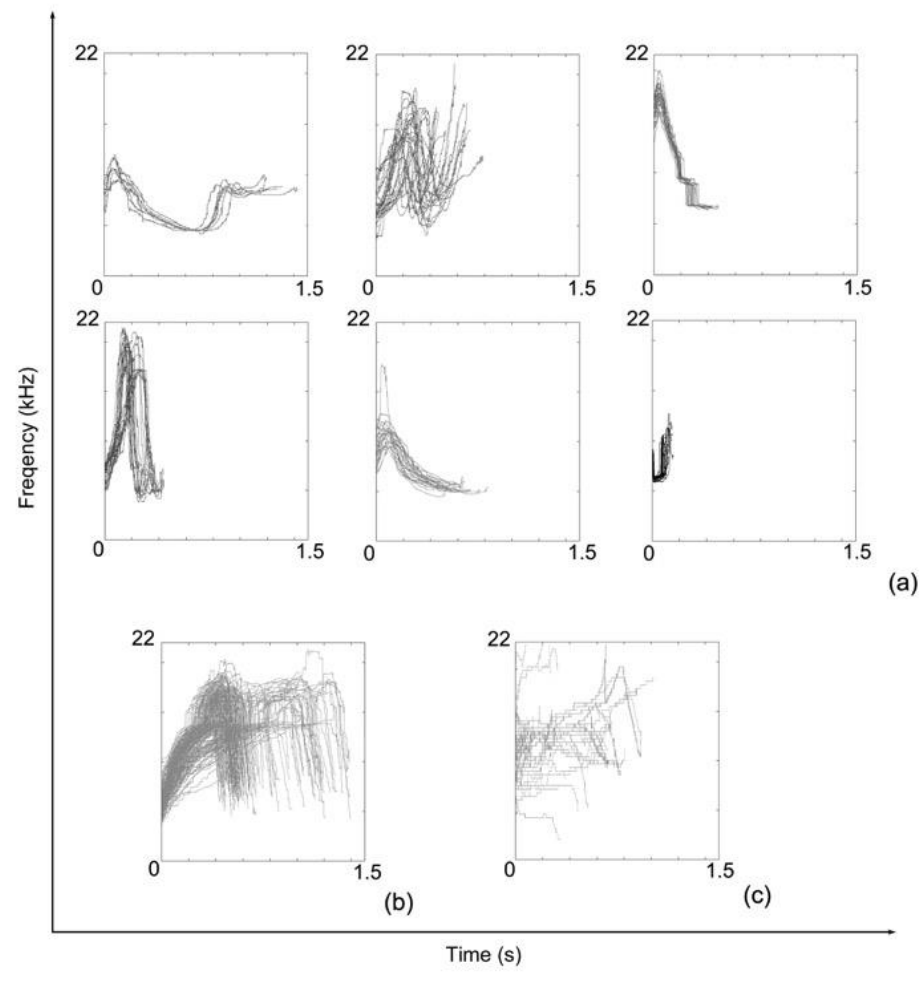


Fig. 2 Whistles plotted in the space defined by principal components. The signature whistles of the captive Risso's dolphin made a distinctive cluster within the range of variation of bottlenose dolphin vocalisations, which was separated from the cluster made by whistles from wild conspecifics

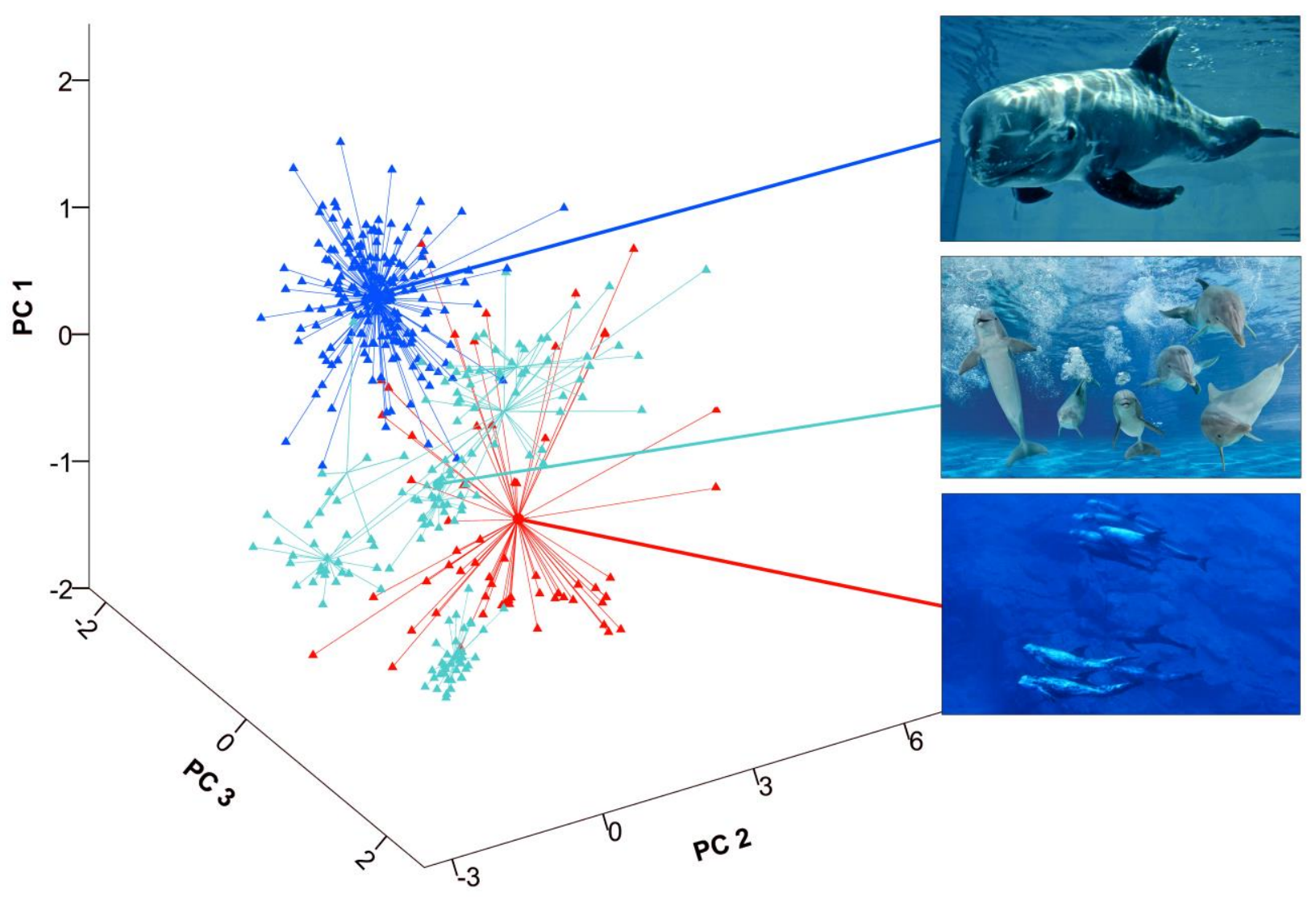

